Cite as: Grohmann, C.H., Riccomini, C., 2009. Comparison of roving-window and searchwindow techniques for characterising landscape morphometry. Computers 83 Geosciences. 35:2164-3169. doi:10.1016/j.cageo.2008.12.014

\title{
Comparison of roving-window and search-window techniques for characterising landscape morphometry
}

\author{
Carlos H. Grohmann, Claudio Riccomini \\ Instituto de Geociências - Universidade de São Paulo, Brasil \\ Rua do Lago, 562, Cidade Universitária, São Paulo, SP, CEP 05508-080 \\ Tel. +55-11-3091-4216, Fax. +55-11-3091-4258
}

\section{Introduction}

Neighbourhood analysis in a Geographical Information System (GIS) calculates the value of a given raster cell from the values of its neighboring cells. Common operations include filtering (high-pass, low-pass, etc) and smoothing (mean, mode) of data, operations that can be done by means of rovingwindows or search-windows. Digital terrain analysis (or geomorphometry) relies on neighbourhood operations to calculate morphometric variables such as slope, aspect, local relief or surface roughness (among many others) at scales ranging from local (i.e., single landforms) to regional (entire mountain chains).

The intent of this paper is to compare both techniques in a multi-scale study of geomorphometry, in central-eastern Brazil. The study area is limited by coordinates $0^{\circ}$ and $26^{\circ} \mathrm{S}$ latitude and $34^{\circ} \mathrm{W}$ and $56^{\circ} \mathrm{W}$ longitude, with approximately $4.900 .000 \mathrm{~km}^{2}$.

The roving-window approach can be considered the standard filter technique in raster GIS operations and in image processing (Demers, 2004; Lillesand et al., 2004). It determines the new value for a given cell in a raster map using a mathematical function (mean, mode, standard deviation etc) of the cells values inside a $n \times n$ neighbourhood (with odd $n$ ) centred in the cell of interest (Fig. 1A). The window is moved one cell at a time across the raster map, until the whole area is processed.

The search-window technique (or searching filter - Shary et al., 2002) is similar to dividing the map into regular tiles (usually square), and calculating a mathematical function inside each tile. A window of arbitrary size is defined, the function is calculated with all the cells that lie inside the window and the resulting value is attributed to the window's geometrical centre (according to its coordinates, not necessarily a cell centre). The search window is then shifted by its E-W or N-S extension and the operation is repeated, in a series of rows and columns (Fig. 1B). The output of this approach is a regular array of points (x,y,z) (Fig. 2B). A simple conversion of these points to a raster format will result either in a map with cells surrounded by null (i.e., nodata) values, if the spatial resolution of the resulting map is the same as the resolution of the original raster used to calculate the variable (Fig. 2C), or in a map with a "blocky" appearance, if the resolution is adjusted to match the search-window size (Fig. 2D). In order to achieve a continuous representation of the results, the points' values can be interpolated (Fig. 2E), using any of the functions available in GIS packages.

In studies of geomorphometry, the search-windows can have their size adjusted to specific feature(s) of the surface, like a lake or a mountain, therefore this approach will describe regional morphometric variables, while roving-windows (fixed sized filter) describe local morphometric variables (Shary et al., 2002).

Given the scale relationships between the size of the roving-window and the shape of the studied surface (topography, for instance), extreme local values (maxima and minima) may be represented in the resulting map as "plateaus", schematically shown as profiles in figure 3B. On the other hand, when working with roving-window analysis, all the cells in the map are taken into account (except for 
those in the edges of the map which doesn't have a full neighbourhood), so there is no risk of "missing" or "shifting" important values, such as local maxima and minima, as can happen with search-window analysis, depending on the size of the window and its position relative to the surface features (Figs. 3C and $\mathrm{D})$.

\section{Experiments and Results}

In order to compare the performance of each technique in a regional-scale analysis, a SRTM_30PLUS Digital Elevation Model (Becker and Sandwell, 2007), with 30-second spatial resolution (about $1 \mathrm{~km}$ ) was used. The roving-window approach was performed with native functions available in GRASS-GIS (Neteler and Mitasova, 2007; GRASS Development Team, 2008), while the search-window method was implemented as a shell script to calculate the desired function within each window and then interpolate the resulting values with Regularised Splines with Tension (RST - Mitasova and Mitas, 1993; Mitasova et al., 2005).

Two morphometric variables were selected in this study, mean slope and local relief. Mean slope was calculated as the arithmetic mean of the slope values and was chosen to represent a "simple" neighbourhood operation, while local relief (or relative relief - Smith, 1935; Ahnert, 1984; Summerfield, 1991), is a measure of the difference between maximum and minimum elevations within a neighbourhood and, in this case, represents a slightly more complex operation. The maps were calculated with roving-windows of $11 \times 11,27 \times 27,55 \times 55$ and $109 \times 109$ cells and with search-windows of $0^{\circ} 06^{\prime} 00^{\prime \prime}\left(0.1^{\circ}\right)$, $0^{\circ} 15^{\prime} 00^{\prime \prime}\left(0.25^{\circ}\right), 0^{\circ} 30^{\prime} 00^{\prime \prime}\left(0.5^{\circ}\right)$ and $1^{\circ} 00^{\prime} 00^{\prime \prime}$. The neighbourhood sizes are similar for both methods (Table 1).

Figure 4 shows processing time needed to calculate the mean slope maps with both methods, according to window size. In our tests we used a computer with an Intel $^{R}$ Core $2 \mathrm{Duo}^{T M} \mathrm{~T}^{\mathrm{T}} 5300$ processor with $1.73 \mathrm{GHz}$ and $2.0 \mathrm{~Gb} \mathrm{RAM}$.

The computational cost of the roving-window analysis is proportional to window size and, to a lesser degree, to the mathematical function. Smaller windows are quickly processed while the amount of cells (and time span) will grow exponentially with window size. As for the search-window method, the situation is opposite. With large windows, the operation is repeated fewer times and the interpolation is faster, since there are less data points. With small windows, the operation has to be repeated many times and the interpolation consumes more system resources.

Summary statistics for all maps are presented in table 2, density plots in figure 5 and maps of local relief in figure 6 . The two approaches yielded consistent statistical results, with asymmetrical distributions and peaks at about the same values. The maps of mean slope are visually very similar for both methods whereas the maps of local relief, although alike, clearly show the "plateau" effect discussed before for large roving-windows (Fig. 6 C), as a pattern of roughly square areas.

Local relief maps calculated with smaller neighbourhoods (Figs. 6 A-B) show regions of high relief in the eastern, southeastern, northeastern, central and central-northern sectors of the study area, surrounding regions of low relief. The high relief correspond to hilly/mountainous landforms developed mainly over crystalline rocks, while the low relief is mostly related to coastal/alluvial plains and sedimentary basins. The maps calculated with larger neighbourhoods (Figs. 6 C-D) show only a simplified vision of the area's morphology and a tendency of homogenisation of values, defining domains of high and low relief.

The observed tendency of homogenisation is related to the size of the neighbourhood, since at different scales, the same landform can be classified as a different feature (Fisher et al., 2004; Schmidt and Andrew, 2005). With windows of $c a .25 \mathrm{~km}$, it is possible to identify single features of the landscape, while windows of $c a .100 \mathrm{~km}$ can only depict the major elements of the landscape. In the same way, the "growth" of regions of high relief with larger windows (compare Figs. 6 A-B and C-D) is due the fact that at smaller scales (i.e., with larger neighbourhoods), the bordering areas of low relief regions will not yield low values, since the higher values of the surrounding areas will also be considered in the calculations. 


\section{Conclusions}

In this article two kinds of neighbourhood analysis were compared, namely the roving-window and the search-window methods. Roving-windows (fixed size filters) provide information about local landform elements, while search-windows can be adjusted to match the size of a feature of interest and provide information about regional geomorphological features.

Despite the differences in implementation and in map patterns (with large window sizes), both methods produced similar statistical results. Given the strong variation in computational cost and processing time, it is recommended that roving-windows should be used with small neighbourhoods and that search-windows are more efficient in regional studies, with large neighbourhoods.

\section{Acknowledgements}

This study was supported by Brazil's State of São Paulo Research Foundation Grant FAPESP 04/06260-5 to Carlos Grohmann. Claudio Riccomini is a Research Fellow of the National Council of Scientific and Technological Development, CNPq Grant 304649/2005-8. The authors express their appreciation to Steve Wise and to the anonymous reviewers, for their valuable comments and critics.

\section{References}

Ahnert, F., 1984. Local relief and the height limits of mountain ranges. American Journal of Science $284(9), 1035-1055$.

Becker, J. J., Sandwell, D. T., 2007. SRTM30_PLUS: Data fusion of SRTM land topography with measured and estimated seafloor topography (Version 3.0), http://topex.ucsd.edu/WWW_html/srtm30_plus.html, [accessed 04 September 2008].

Demers, M. N., 2004. Fundamentals of Geographic Information Systems. John Wiley \& Sons, New York, 468pp.

Fisher, P., Wood, J., Cheng, T., 2004. Where is Helvellyn? Fuzziness of multiscale landscape morphometry. Transactions of the Institute of British Geographers 29(1), 106-128. doi:10.1111/j.00202754.2004.00117.x.

GRASS Development Team, 2008. Geographic Resources Analysis Support System (GRASS GIS) Software, Version 6.3.0, http://grass.osgeo.org, [accessed 04 September 2008].

Lillesand, T. M., Kiefer, R. W., Chipman, J. W., 2004. Remote Sensing and Image Interpretation. John Wiley \& Sons, Chichester UK, 763pp.

Mitasova, H., Mitas, L., 1993. Interpolation by regularized spline with tension:I Theory and implementation. Mathematical Geology 25(6), 641-655. doi:10.1007/BF00893171.

Mitasova, H., Mitas, L., Harmon, R. S., 2005. Simultaneous spline approximation and topographic analysis for lidar elevation data in open source GIS. IEEE Geoscience and Remote Sensing Letters $2(4), 375-379$.

Neteler, M., Mitasova, H., 2007. Open Source GIS : A GRASS GIS Approach, Third Edition. The International Series in Engineering and Computer Science, Vol. 773. Springer, New York, 406pp.

Schmidt, J., Andrew, R., 2005. Multi-scale landform characterization. Area 37(3), 341-350. doi:10.1111/j.1475-4762.2005.00638.x.

Shary, P. A., Sharaya, L. S., Mitusov, A. V., 2002. Fundamental quantitative methods of land surface analysis. Geoderma 107(1-2), 1-32. doi:10.1016/S0016-7061(01)00136-7. 
Smith, G. H., 1935. The relative relief of Ohio. Gographic Review 25(2), 272-284.

Summerfield, M. A., 1991. Sub-aerial denudation of passive margins: regional elevation versus local relief models. Earth and Planetary Science Letters 102(3-4), 460-469. doi:10.1016/0012821X(91)90036-H.

\section{Figures}

\section{A) roving-window}

original data

\begin{tabular}{|c|c|c|c|c|c|}
\hline 10 & 1 & 5 & 9 & 4 & 9 \\
\hline 7 & 0 & 5 & 2 & 9 & 2 \\
\hline 4 & 8 & 3 & 3 & 4 & 1 \\
\hline 7 & 7 & 8 & 9 & 5 & 8 \\
\hline 5 & 5 & 3 & 6 & 1 & 5 \\
\hline 2 & 0 & 6 & 7 & 10 & 9 \\
\hline
\end{tabular}

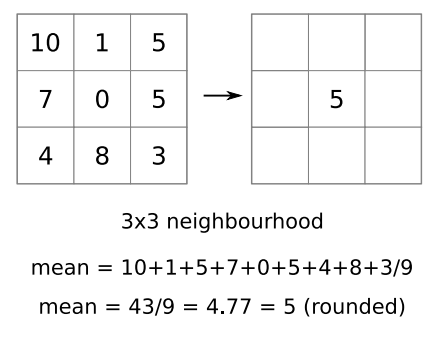

B) search-window

original data

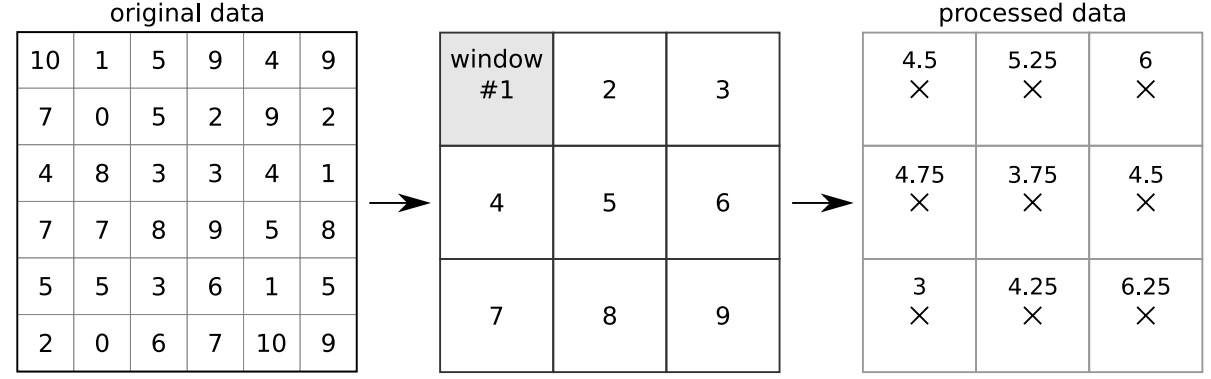

Figure 1. A) Roving-window analysis (3x3 neighbourhood); B) Search-window analysis. Mean operation. 

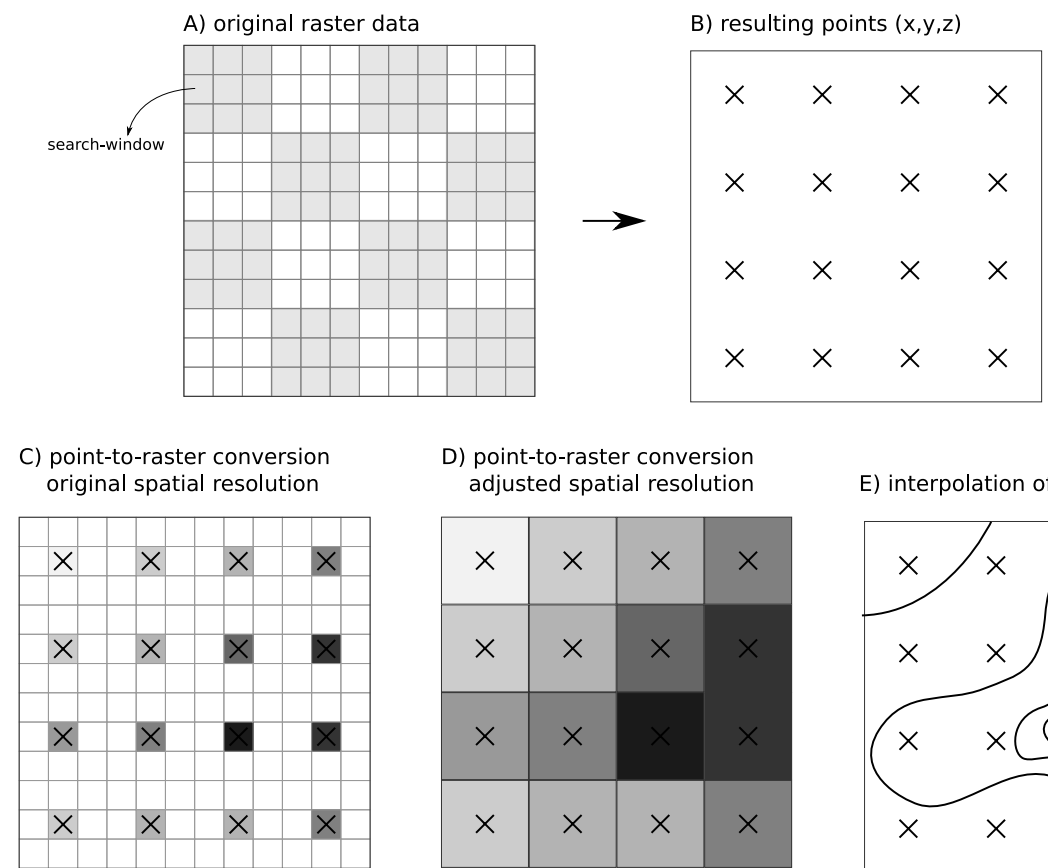

D) point-to-raster conversion adjusted spatial resolution

\begin{tabular}{|c|c|c|c|}
\hline$x$ & $x$ & $x$ & $x$ \\
\hline$x$ & $x$ & $x$ & $x$ \\
\hline$x$ & $x$ & $x$ & $x$ \\
\hline$x$ & $x$ & $x$ & $x$ \\
\hline
\end{tabular}

E) interpolation of values

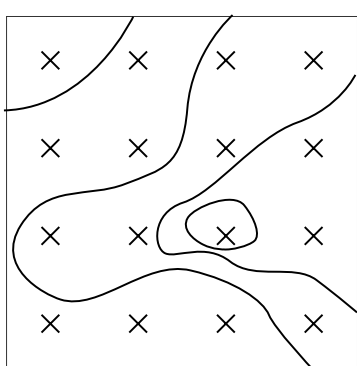

Figure 2. Conversion of results from a search-window analysis. A) Original data. Checkerboard pattern indicates positon of search-windows; B) Resulting points (x,y,z,); C) Simple point-to-raster conversion, with same spatial resolution as original raster map; D) Point-to-raster conversion, adjusting spatial resolution to match search-window size; E) Interpoation of points values.
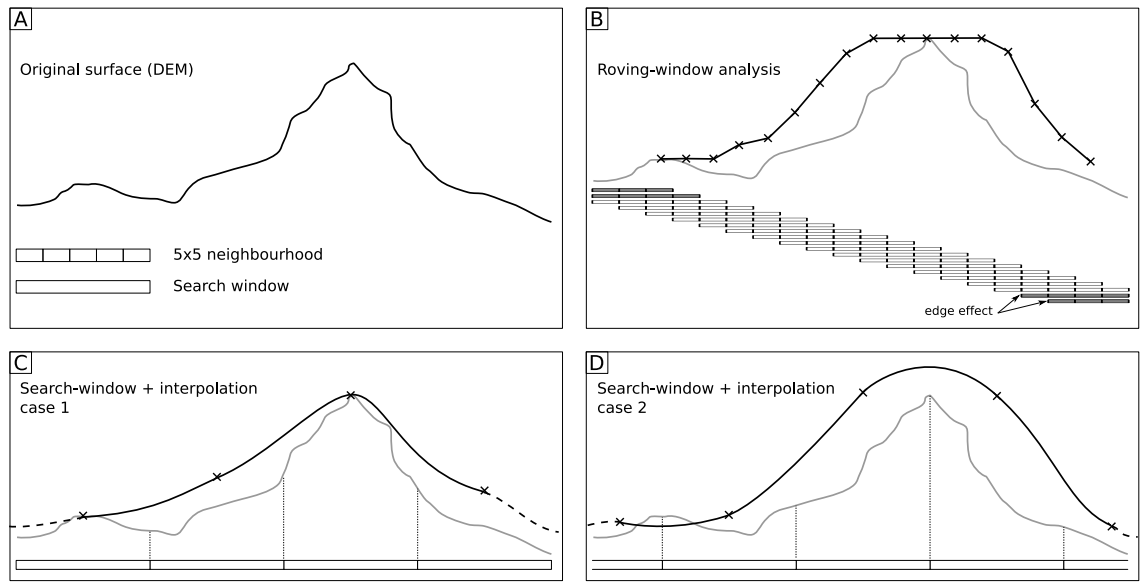

Figure 3. Comparison between roving-window and search-window (maximum value). A) Original surface (elevation); B) Roving-window (5x5); C) Search-window - case 1; D) Search-window - case 2. 


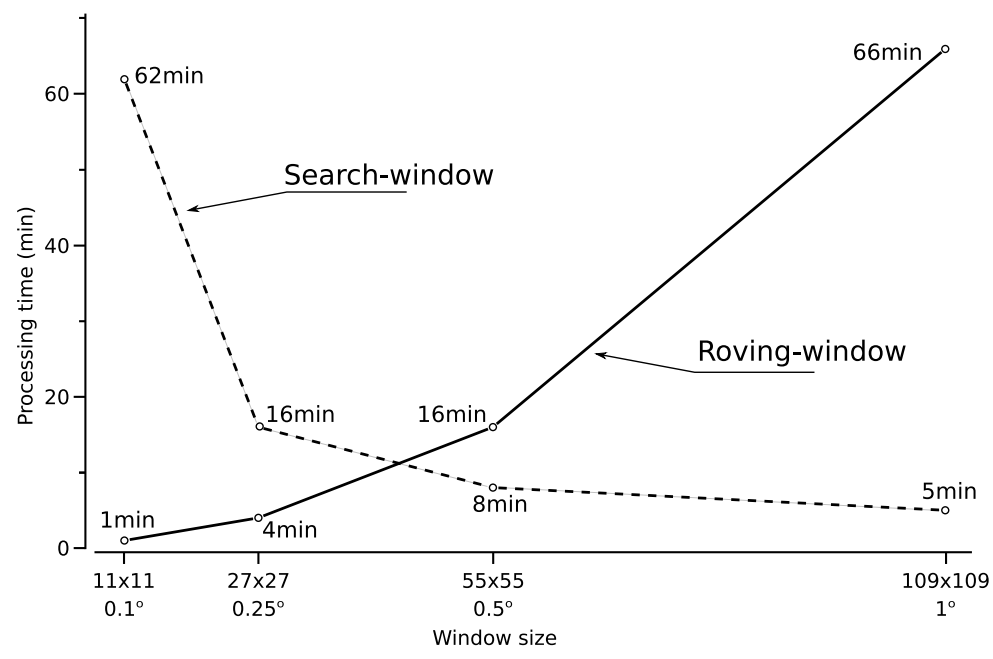

Figure 4. Processing time for mean slope operation, using roving-windows and search-windows, according to window size.
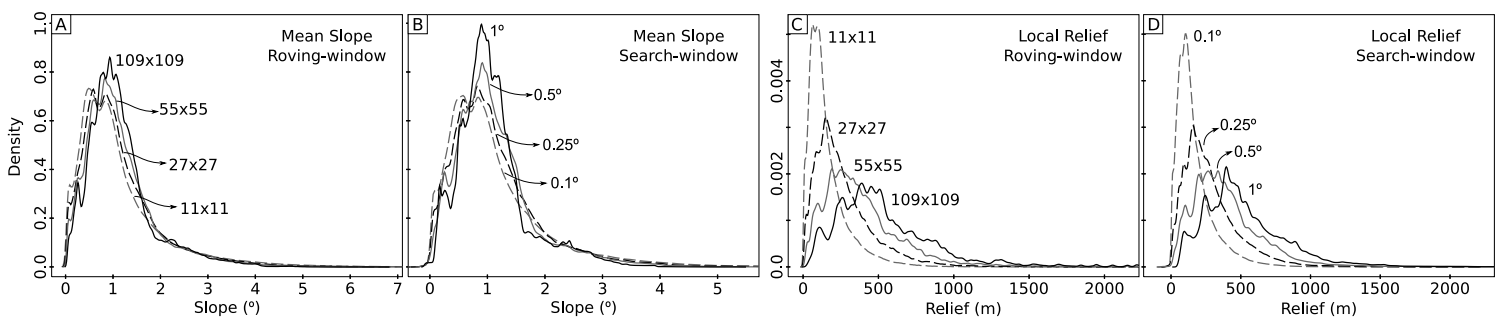

Figure 5. Density plots of morphometric maps. A) Mean slope, roving-window; B) Mean slope, searchwindow; D) Local relief, roving-window; E) Local relief, search-window. 

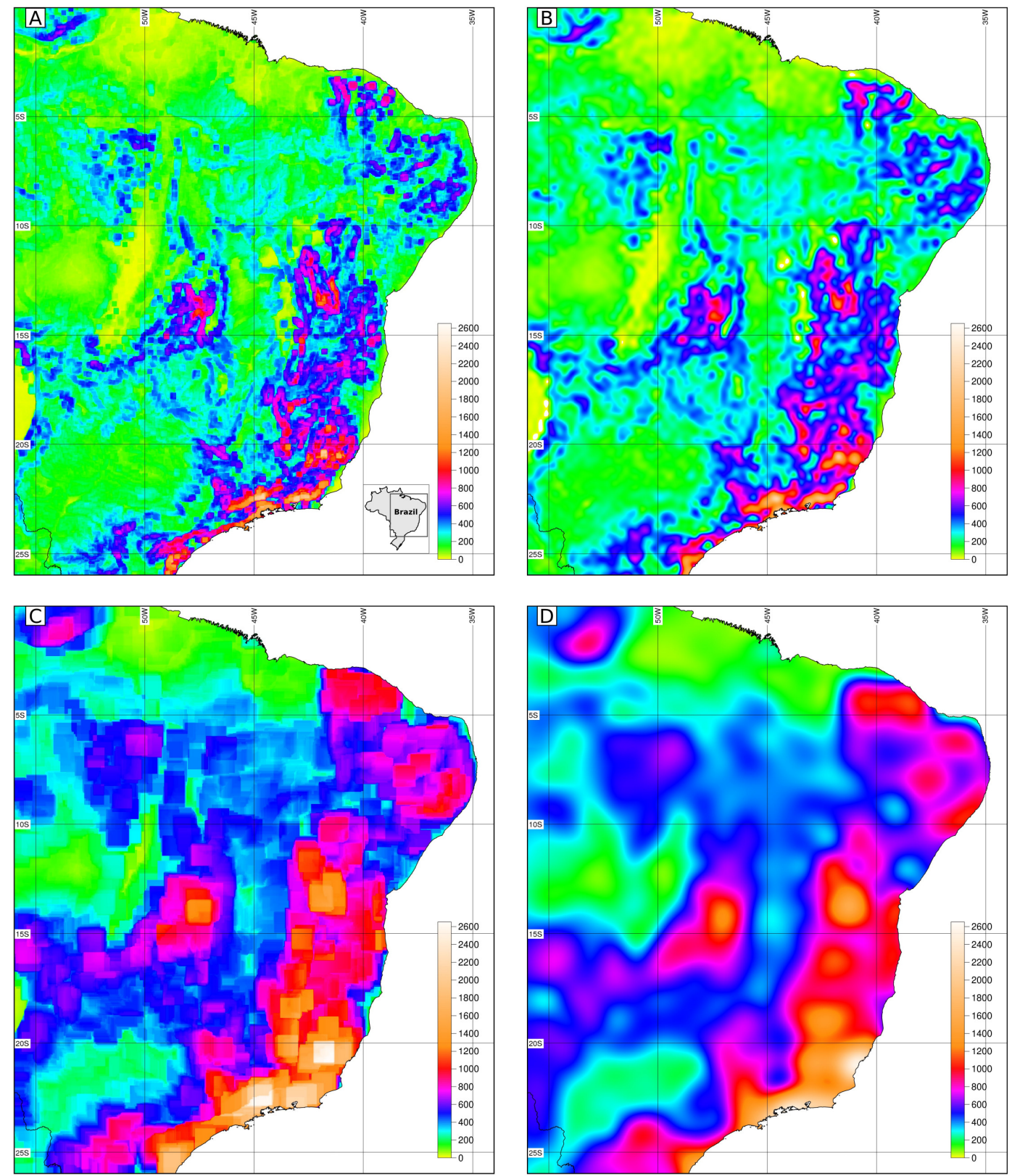

Figure 6. Maps of local relief. A) Roving-window, 27x27 cells; B) Search-window, $0.25^{\circ}$; C) Rovingwindow, 109x109 cells; D) Search-window, $1^{\circ}$. 


\section{Tables}

Table 1. Neighbourhoods used to calculate morphometric maps (sizes in kilometers at the Equator).

\begin{tabular}{ll} 
window & size $(\mathrm{km})$ \\
\hline $0,1^{\circ}$ & 11,112 \\
$11 \times 11$ & 10,186 \\
$0,25^{\circ}$ & 27,78 \\
$27 \times 27$ & 25,002 \\
$0,5^{\circ}$ & 55,56 \\
$55 \times 55$ & 50,93 \\
$1^{\circ}$ & 111,12 \\
$109 \times 109$ & 100,934
\end{tabular}

Table 2. Summary statistics of morphometric maps.

\begin{tabular}{llllllll}
\hline Variable & Window & Min. & $1^{\text {st }} \mathrm{Qu}$. & Median & Mean & $3^{\text {rd }} \mathrm{Qu}$. & Max. \\
\hline Mean & $11 \times 11$ & 0.0000 & 0.5199 & 0.8891 & 1.1490 & 1.4240 & 14.3600 \\
slope $\left(^{\circ}\right)$ & $27 \times 27$ & 0.0150 & 0.5804 & 0.9454 & 1.1490 & 1.4520 & 10.9700 \\
roving-window) & $55 \times 55$ & 0.0248 & 0.6375 & 0.9853 & 1.1490 & 1.4410 & 9.4300 \\
& $109 \times 109$ & 0.0441 & 0.7068 & 1.0190 & 1.1500 & 1.4030 & 6.7620 \\
\hline Mean & $0.1^{\circ}$ & -0.6272 & 0.5377 & 0.9084 & 1.1450 & 1.4380 & 11.8500 \\
slope $\left(^{\circ}\right)$ & $0.25^{\circ}$ & -0.2556 & 0.6001 & 0.9634 & 1.1370 & 1.4410 & 9.2340 \\
search-window) $^{\circ}$ & $0 .^{\circ}$ & -0.1796 & 0.6585 & 0.9911 & 1.1250 & 1.4060 & 6.5820 \\
& $1^{\circ}$ & -0.0952 & 0.7106 & 0.9896 & 1.0920 & 1.3180 & 5.4380 \\
\hline Local & $11 \times 11$ & 0.0 & 71.0 & 121.0 & 161.9 & 205.0 & 2130.0 \\
relief $(\mathrm{m})$ & $27 \times 27$ & 2.0 & 134.0 & 220.0 & 273.7 & 354.0 & 2209.0 \\
roving-window) $^{\circ}$ & $55 \times 55$ & 13.0 & 208.0 & 335.0 & 393.9 & 501.0 & 2558.0 \\
& $109 \times 109$ & 27.0 & 314.0 & 469.0 & 544.2 & 690.0 & 2676.0 \\
\hline Local & $0.1^{\circ}$ & -90.16 & 78.8 & 131.5 & 170.7 & 217.2 & 2212 \\
relief $(\mathrm{m})$ & $0.25^{\circ}$ & -48.62 & 146.6 & 237.5 & 287.0 & 371.0 & 2192 \\
search-window) $^{\circ}$ & $0.5^{\circ}$ & -72.35 & 222.9 & 349.3 & 400.9 & 509.4 & 2339 \\
& $1^{\circ}$ & 40.40 & 323.2 & 466.9 & 530.2 & 670.5 & 2579 \\
\hline
\end{tabular}

